\title{
Identification of risk factors for postoperative stage 3 acute kidney injury in patients who received surgical repair for acute type A aortic dissection
}

\author{
Zhigang Wang ${ }^{1}$, Min Ge', Zheyun Wang ${ }^{1}$, Cheng Chen ${ }^{1}$, Lichong Lu', Lifang Zhang ${ }^{2}$ and Dongjin Wang ${ }^{\text {** }}$
}

\begin{abstract}
Background: Acute kidney injury (AKI) is a serious complication that often occurred after acute type A aortic dissection (ATAAD) surgery. Previous studies proved that the Kidney Disease Improving Global Outcomes (KDIGO) defined stage 3 AKI was associated with lower long-term survival rate. However, the risk factors for developing stage 3 AKI had not been identified. The aim of the study was to explore the risk factors for developing KDIGO stage 3 after ATAAD operation.
\end{abstract}

Methods: This study included 993 patients who received ATAAD operation from 2014 to 2019 at the Nanjing Drum Tower Hospital. Postoperative AKI was diagnosed according to the KDIGO criteria. Multivariate logistic regression analyses were applied to identify risk factors for stage 3 AKI. Kaplan-Meier survival analyses and Cox proportional hazards regression model were conducted to explore the association between different AKI stages and postoperative survival rate.

Results: The mean age of all enrolled patients was $53.0 \pm 13.1$ years. A total of 236 (23.8\%) patients suffered postoperative stage $3 \mathrm{AKI}$ including 165 patients who required renal replacement therapy. Advanced age (odds ratio [OR] $1.031 ; 95 \%$ confidence interval $[C I] 1.005-1.057 ; P=0.018)$, prolonged cardiopulmonary bypass (CPB) duration (OR $1.010 ; 95 \% \mathrm{Cl} 1.002-1.018 ; P=0.013)$, and higher drainage volume $24 \mathrm{~h}$ after surgery (OR 1.000; 95\% Cl 1.000-1.001; $P=0.033$ ) were identified as independent risk factors for developing stage $3 \mathrm{AKI}$. In addition, our result showed that the mortality rate was correlated significantly with the severity of AKI defined by KDIGO criteria and the Cox regression analysis showed that only stage $3 \mathrm{AKI}$, but not stage 1 and 2, was an independent risk factor for mortality (Hazard ratio $10.365,95 \% \mathrm{Cl} 4.208$ to $25.528 ; P<0.001$ ) after adjusting for important confounding factors.

Conclusions: Our study suggested that stage 3 postoperative AKI was significantly associated with decreased postoperative survival rate after ATAAD surgery. Advanced age, increased CPB duration and drainage volume $24 \mathrm{~h}$ after surgery were identified as risk factors for developing stage 3 AKI.

Keywords: Acute kidney injury, Type A aortic dissection, Outcomes

*Correspondence: glyywdj@163.com

1 Department of Cardio-thoracic Surgery, Affiliated Drum Tower Hospital, Medical School of Nanjing University, Zhongshan Road 321, Nanjing 210008, China

Full list of author information is available at the end of the article

\section{Introduction}

It is well accepted in the field that acute kidney injury (AKI) is a common and serious complication after acute type A aortic dissection (ATAAD) surgery. However, the incidence of AKI after aortic arch surgery varied 
widely (20-67\%) in previous studies largely due to the lack of consensus in AKI definition until 2012 when the Kidney Disease Improving Global Outcome (KDIGO) criteria was published [1-5].

Inconsistent association between the development of postoperative AKI and long-term adverse outcomes in patients with ATAAD had been suggested in previous studies. Some studies demonstrated that only stage 3 AKI was significantly associated with lower long-term survival $[6,7]$, whereas others have found all stages postoperative AKI increased the mortality of patients with ATAAD [2, 3, 8]. However, most of these studies were conducted in a relatively small population and designed differently.

The current study not only aimed to decipher the association between different stages of AKI and disease outcomes but also to identify the risk factors for developing stage 3 AKI in patients after receiving ATAAD surgery. We present the following article in accordance with the STROBE reporting checklist.

\section{Materials and methods Study population}

We retrospectively reviewed the medical records of 1052 patients who received ATAAD surgery at Nanjing Drum Tower Hospital between January 2014 and December 2019. Patients who were admitted to our hospital more than $48 \mathrm{~h}$ after symptom onset were excluded from the analysis $(n=13)$. Patients who required renal replacement therapy (RRT) before surgery $(n=27)$ were also excluded due to difficulty in measuring the progression of renal dysfunction. Patients who died during surgery or within $24 \mathrm{~h}$ after surgery $(n=19)$ were excluded when the death was considered irrelevant with postoperative renal dysfunction. The protocol of this study was approved by the institutional review board and individual consent was waived considering the retrospective nature of the study.

The stage 3 AKI was defined according to the serum creatinine $(\mathrm{sCr})$ component of the KDIGO criteria at day 7 after the surgery $(>3.0 \times$ baseline $\mathrm{sCr}$ or increase in $\mathrm{sCr}$ to $\geq 4.0 \mathrm{mg} / \mathrm{dL}$ or initiation of RRT) (Table 1 ). This study did not apply the urine output as the criteria in defining stage 3 AKI considering the high risk of inaccuracy in this retrospective study. Preoperative hepatic dysfunction was diagnosed in patients with Model of End-Stage Liver Disease (MELD) score $\geq 12$. Routine follow up of patients' general health status was conducted by telephone contact since 2014 once every year. If patients had died at the time of contact, the date and the cause of deaths was collected. All patients
Table 1 Kidney Disease Improving Global Outcomes (KDIGO) criteria for acute kidney injury

\begin{tabular}{ll}
\hline Stage & Serum creatinine $(\mathbf{s} \mathbf{C r})$ increase \\
\hline 1 & $1.5-1.9$ times baseline or $\geq 0.3 \mathrm{mg} / \mathrm{dL}$ increase \\
2 & $2.0-2.9$ times baseline \\
3 & $>3.0$ times baseline or increase in $\mathrm{s} \mathrm{Cr}$ \\
& to $\geq 4.0 \mathrm{mg} / \mathrm{dL}$ or initiation of renal replace- \\
& ment therapy \\
\hline
\end{tabular}

were divided into the stage 3 AKI group and the control group.

\section{Surgical procedure}

The surgical techniques applied in the study was described in detail in a previous study [9]. Briefly, the root procedures included direct repair or replacement of inclusion root, Bentall procedure, or David procedure. The distal arch repair consisted of hemi-arch replacement, island arch replacement, total arch replacement, triple-branched stent, and fenestrated stent depending on patient's preoperative status, entry tear location, and aortic diameter, as described previously.

\section{Statistical analysis}

Continuous variables were expressed as mean \pm standard deviation or median with interquartile range as appropriate. Categorical variables were presented as frequencies with percentages. The $\chi^{2}$ test or Fisher exact test was used for comparing categorical variables, whereas the $t$-test or Mann-Whitney $U$-test was chose for examining continuous variables.

To reduce selection bias, one-to-one propensity score (PS) matching was conducted between two groups. All the pre-operative variables listed in Table 2 and introoperative variables listed in Table 3 were included in the analysis. The PS for each patient was estimated using the logistic regression model and matched to the nearest neighboring point with a tolerance level on the maximum PS distance (callipers of width 0.2 standard deviations of the logit of the PS).

Multivariate logistic regression analysis was performed (stepwise enter method) using variables identified in the univariable analyses $(P$-value $<0.20)$ to identify independent risk factors for developing stage 3 AKI after surgery. We used Kaplan-Meier methods and multivariate Cox proportional hazards regression to assess the impact of AKI for postoperative mortality. For Cox regression analysis, all variables with a $P$-value $<0.20$ identified in univariable analysis were included in the model. A forward stepwise procedure was applied to introduce variables to the final models. A $P$-value less than 0.05 was considered 
Table 2 Baseline characteristics of the unmatched and propensity matched groups

\begin{tabular}{|c|c|c|c|c|c|c|c|}
\hline \multirow[t]{2}{*}{ Variables } & \multirow{2}{*}{$\begin{array}{l}\text { Total } \\
(n=993)\end{array}$} & \multicolumn{3}{|l|}{ Overall cohort } & \multicolumn{3}{|l|}{ PSM Cohort } \\
\hline & & $\begin{array}{l}\text { Stage } 3 \\
(n=236)\end{array}$ & $\begin{array}{l}\text { Control } \\
(n=757)\end{array}$ & $P$ value* & $\begin{array}{l}\text { Stage } 3 \\
(n=119)\end{array}$ & $\begin{array}{l}\text { Control } \\
(n=119)\end{array}$ & $P$ value* \\
\hline \multicolumn{8}{|l|}{ Demographic data } \\
\hline Age (year) & $53.0 \pm 13.1$ & $54.0 \pm 13.4$ & $52.7 \pm 13.1$ & 0.186 & $53.7 \pm 13.3$ & $51.2 \pm 12.3$ & 0.141 \\
\hline Male (\%) & $730(73.5)$ & $179(75.8)$ & $551(72.8)$ & 0.352 & $92(77.3)$ & $93(78.2)$ & 0.876 \\
\hline $\mathrm{BMI}\left(\mathrm{kg} / \mathrm{m}^{2}\right)$ & $25.6 \pm 4.8$ & $26.3 \pm 4.8$ & $25.4 \pm 4.8$ & 0.036 & $26.5 \pm 4.8$ & $26.0 \pm 4.4$ & 0.371 \\
\hline \multicolumn{8}{|l|}{ Medical history } \\
\hline Hypertension (\%) & $715(72.0)$ & $186(78.8)$ & $529(69.9)$ & 0.008 & $87(73.1)$ & $91(76.5)$ & 0.550 \\
\hline Diabetes mellitus (\%) & $23(2.3)$ & $4(1.7)$ & $19(2.5)$ & 0.467 & $0(0)$ & $3(2.5)$ & 0.247 \\
\hline Previous cardiac surgery (\%) & $44(4.4)$ & $14(5.9)$ & $30(4.0)$ & 0.199 & $6(5.0)$ & $5(4.2)$ & 0.758 \\
\hline $\begin{array}{l}\text { Previous coronary artery disease } \\
\text { (\%) }\end{array}$ & $34(3.4)$ & $11(4.7)$ & $23(3.0)$ & 0.231 & $3(2.5)$ & $2(1.7)$ & 1.000 \\
\hline Cerebrovascular disease (\%) & $36(3.6)$ & $9(3.8)$ & $27(3.6)$ & 0.859 & $6(5.0)$ & $1(0.8)$ & 0.119 \\
\hline $\operatorname{LVEF}(\%)$ & $55.1 \pm 6.6$ & $54.2 \pm 5.9$ & $55.3 \pm 6.7$ & 0.489 & $55.1 \pm 5.6$ & $54.0 \pm 8.7$ & 0.728 \\
\hline $\begin{array}{l}\text { Time from symptom onset to admis- } \\
\text { sion }\end{array}$ & $10.7 \pm 6.0$ & $12.3 \pm 7.1$ & $11.4 \pm 6.4$ & 0.274 & $12.5 \pm 6.8$ & $11.7 \pm 6.5$ & 0.259 \\
\hline Pericardial tamponade (\%) & $166(16.7)$ & $55(23.3)$ & $111(14.7)$ & 0.002 & $21(17.6)$ & $17(14.3)$ & 0.479 \\
\hline DeBakey type I (\%) & $816(82.2)$ & $207(87.7)$ & $609(80.4)$ & 0.011 & $103(86.6)$ & $102(85.7)$ & 0.851 \\
\hline MELD score $\geq 12(\%)$ & $268(27.2)$ & $103(45.2)$ & $165(21.8)$ & $<0.001$ & $38(33.0)$ & $31(26.1)$ & 0.241 \\
\hline \multicolumn{8}{|l|}{ Preoperative laboratory data } \\
\hline WBC $\left(10^{9} / L\right)$ & $11.7 \pm 11.1$ & $12.3 \pm 4.7$ & $11.5 \pm 12.4$ & 0.339 & $12.9 \pm 5.2$ & $11.6 \pm 4.2$ & 0.171 \\
\hline Hemoglobin (g/L) & $122.4 \pm 29.0$ & $121.4 \pm 41.2$ & $122.8 \pm 24.0$ & 0.630 & $120.8 \pm 48.7$ & $117.4 \pm 26.6$ & 0.381 \\
\hline $\operatorname{PLT}\left(10^{9} / \mathrm{L}\right)$ & $150.9 \pm 86.2$ & $142.6 \pm 62.7$ & $153.5 \pm 92.3$ & 0.091 & $151.8 \pm 59.0$ & $145.7 \pm 62.4$ & 0.440 \\
\hline $\mathrm{sCr}(\mu \mathrm{mol} / \mathrm{L})$ & $81.0(61.8,114.2)$ & $101.2(68.1,175.8)$ & $77.6(60.0,104.1)$ & $<0.001$ & $111.1 \pm 84.4$ & $108.0 \pm 88.3$ & 0.784 \\
\hline Bun (mmol/L) & $8.2 \pm 4.0$ & $9.9 \pm 5.6$ & $7.7 \pm 3.2$ & $<0.001$ & $8.3 \pm 3.9$ & $8.6 \pm 4.1$ & 0.658 \\
\hline $\operatorname{ALB}(g / L)$ & $36.5 \pm 5.0$ & $35.6 \pm 5.9$ & $36.8 \pm 4.7$ & 0.008 & $36.5 \pm 5.8$ & $36.3 \pm 4.9$ & 0.758 \\
\hline $\mathrm{ALT}(\mathrm{U} / \mathrm{L})$ & $25.6(15.7,46.8)$ & $30.3(15.2,81.1)$ & $22.3(14.3,41.1)$ & $<0.001$ & $29.6(17.4,74.9)$ & $25.9(14.2,41.5)$ & 0.113 \\
\hline $\mathrm{CRP}(\mathrm{mg} / \mathrm{dL})$ & $23.6(5.0,81.6)$ & $19.2(4.8,66.4)$ & $22.2(4.4,67.5)$ & 0.628 & $19.2(5.2,67.2)$ & $24.9(4.5,106.4)$ & 0.171 \\
\hline Triglyceride (mmol/L) & $1.0(0.7,1.5)$ & $1.1(0.7,1.6)$ & $0.9(0.7,1.5)$ & 0.166 & $1.1(0.8,1.6)$ & $1.0(0.8,1.4)$ & 0.353 \\
\hline Total bilirubin ( $\mu \mathrm{mol} / \mathrm{L})$ & $15.8(11.1,23.1)$ & $14.6(10.0,23.1)$ & $15.2(11.3,22.2)$ & 0.685 & $17.7 \pm 15.4$ & $18.5 \pm 15.4$ & 0.674 \\
\hline INR & $1.1(1.0,1.2)$ & $1.3 \pm 0.8$ & $1.2 \pm 0.7$ & $<0.001$ & $1.2 \pm 0.5$ & $1.1 \pm 0.2$ & 0.060 \\
\hline D-dimer (ng/mL) & $4.6(2.3,9.3)$ & $4.9(2.9,12.3)$ & $3.9(2.1,7.1)$ & 0.001 & $4.7(2.9,9.5)$ & $6.0(3.1,11.5)$ & 0.868 \\
\hline \multicolumn{8}{|l|}{ Preoperative CTA } \\
\hline Involving the left renal artery (\%) & $394(77.0)$ & $91(77.0)$ & $303(79.7)$ & 0.419 & $45(73.8)$ & $44(72.1)$ & 0.596 \\
\hline Involving the right renal artery (\%) & $440(87.6)$ & $100(85.4)$ & $340(89.9)$ & 0.386 & $53(78.5)$ & $45(74.2)$ & 0.479 \\
\hline
\end{tabular}

Data presented as $\mathrm{n}(\%)$, median (IQR), or mean \pm standard deviation

$B M I$ body mass index; $L V E F$ left ventricular ejection fraction; $M E L D$ model of end-stage liver disease; $W B C$ white blood cell; $P L T$ platelet; $s C r$ serum creatinine; $B U N$ blood urea nitrogen; $A L B$ albumin; $A L T$ alanine transaminase; $C R P$ c-reactive protein; INR international normalized ratio; CTA computed tomography angiography; PSM propensity score matching

${ }^{*} P$ values indicate differences between stage $3 \mathrm{AKI}$ and control group patients. $P<0.05$ was considered statistically significant

statistically significant. All analyses were conducted with SPSS software (version 25, SPSS Inc, Chicago, IL).

\section{Results}

A total of 993 patients were eventually enrolled in this study. The patients were predominantly male (73.5\%), with a mean age of $53 \pm 13$ years (range 19-87). Postoperative AKI was identified in 528 patients (53.6\%) including $161(16.2 \%)$ stage 1, 131 (13.2\%) stage 2, and $236(23.8 \%)$ stage 3. A total of 238 patients (119 pairs) selected by this PS-based matching procedure with similar baseline characteristics were eventually enrolled in the analysis.

Patient baseline demographic information was presented in Table 2. For the unmatched patients, compared to the control group, patients with increased body weight and hypertension diagnosis were more commonly occurred in the stage 3 AKI group. Unsurprisingly, the baseline serum creatinine $(\mathrm{sCr})$ level was significantly 
Table 3 Operative variables of the unmatched and propensity matched groups

\begin{tabular}{|c|c|c|c|c|c|c|c|}
\hline \multirow[t]{2}{*}{ Variables } & \multirow{2}{*}{$\begin{array}{l}\text { Total } \\
(n=993)\end{array}$} & \multicolumn{3}{|c|}{ Overall cohort } & \multicolumn{3}{|l|}{ PSM Cohort } \\
\hline & & $\begin{array}{l}\text { Stage } 3 \\
(n=236)\end{array}$ & $\begin{array}{l}\text { Control } \\
(n=757)\end{array}$ & $P$ value* & $\begin{array}{l}\text { Stage } 3 \\
(n=119)\end{array}$ & $\begin{array}{l}\text { Control } \\
(n=119)\end{array}$ & $P$ value* \\
\hline TAR (\%) & $478(48.1)$ & $131(55.5)$ & $347(45.8)$ & 0.009 & $71(59.7)$ & $75(63.0)$ & 0.594 \\
\hline CABG (\%) & $59(5.9)$ & $22(9.3)$ & $37(4.9)$ & 0.012 & $12(10.1)$ & $10(8.4)$ & 0.654 \\
\hline CPB time (min) & $233.8 \pm 68.0$ & $258.6 \pm 74.6$ & $226.1 \pm 63.9$ & $<0.001$ & $258.3 \pm 66.2$ & $261.8 \pm 73.3$ & 0.701 \\
\hline Aortic cross-clamp time (min) & $164.2 \pm 55.6$ & $176.7 \pm 61.6$ & $160.3 \pm 53.1$ & $<0.001$ & $180.8 \pm 62.2$ & $182.9 \pm 61.7$ & 0.801 \\
\hline DHCA time (min) & $29.3 \pm 12.9$ & $32.1 \pm 13.5$ & $28.5 \pm 12.6$ & $<0.001$ & $32.0 \pm 14.5$ & $29.8 \pm 11.8$ & 0.216 \\
\hline
\end{tabular}

Data presented as $\mathrm{n}(\%)$, median (IQR), or mean \pm standard deviation

TAR total arch replacement; $C A B G$ coronary artery bypass graft; $C P B$ cardiopulmonary bypass; $D H C A$ deep hypothermic circulatory arrest; $P S M$ propensity score matching

* $P$ values indicate differences between stage $3 \mathrm{AKI}$ and control group patients. $P<0.05$ was considered statistically significant

increased among patients in the stage 3 AKI group compared to the control group $(P<0.001)$. However, no significant difference of time from symptom onset to admission and renal artery involvement was observed between two groups. In the PS model, the baseline characteristics of the PS matched groups did not reveal any significant differences.

Patient surgical parameters were shown in Table 3. Before PS matching, our data indicated that the cardiopulmonary bypass $(\mathrm{CPB})$ time $(P<0.001)$, aortic crossclamp time $(P<0.001)$, and deep hypothermic circulatory arrest time $(P<0.001)$ were all significantly prolonged in patients who developed stage 3 AKI. After PS matching, the intro-operative variables showed no significant differences between the two groups.

The postoperative outcomes are summarized in Table 4. Before matching, a total of 165 patients (16.6\%) required temporary RRT after surgery and 86 (52.1\%) of them developed dialysis-dependent end-stage renal disease. Furthermore, mechanical ventilation duration, intensive care unit (ICU), and hospital stay were prolonged in patients who developed stage 3 AKI compared to controls. Furthermore, the 30-Day mortality was $30.5 \%$ in the stage 3 group and $7.5 \%$ in the control group with a significant difference. In the PS matched analysis, ICU stay time and the 30-Day mortality consistently showed significant difference between two groups.

Next, multivariate logistic analyses were conducted which suggested that advanced age (odds ratio [OR] 1.031; 95\% confidence interval [CI] 1.005-1.057; $P=0.018$ ), prolonged CPB duration (OR 1.010; $95 \% \mathrm{CI}$ $1.002-1.018 ; P=0.013)$, and higher drainage volume $24 \mathrm{~h}$ after surgery (OR 1.000; 95\% CI 1.000-1.001; $P=0.033$ )

Table 4 Postoperative variables of the unmatched and propensity matched groups

\begin{tabular}{|c|c|c|c|c|c|c|c|}
\hline \multirow[t]{2}{*}{ Variables } & \multirow{2}{*}{$\begin{array}{l}\text { Total } \\
(n=993)\end{array}$} & \multicolumn{3}{|l|}{ Overall cohort } & \multicolumn{3}{|l|}{ PSM cohort } \\
\hline & & $\begin{array}{l}\text { Stage } 3 \\
(n=236)\end{array}$ & $\begin{array}{l}\text { Control } \\
(n=757)\end{array}$ & $P$ value* & $\begin{array}{l}\text { Stage } 3 \\
(n=119)\end{array}$ & $\begin{array}{l}\text { Control } \\
(n=119)\end{array}$ & $P$ value* \\
\hline Drainage volume $24 \mathrm{~h}$ after surgery $(\mathrm{mL})$ & $720.5 \pm 650.0$ & $950.0 \pm 839.1$ & $652.3 \pm 565.2$ & $<0.001$ & $975.0 \pm 926.4$ & $790.4 \pm 729.1$ & 0.099 \\
\hline Re-exploration for bleeding (\%) & $36(3.6)$ & $15(6.4)$ & $21(2.8)$ & 0.010 & $8(6.7)$ & $2(1.7)$ & 0.053 \\
\hline 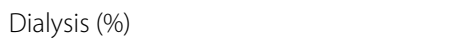 & $165(16.6)$ & $165(69.9)$ & $0(0)$ & $<0.001$ & $80(67.2)$ & $0(0)$ & $<0.001$ \\
\hline Ventilation time (hour) & $17.0(11.0,43.0)$ & $26.0(15.0,90.0)$ & $15.0(11.0,28.8)$ & $<0.001$ & $34.0(16.2,106.8)$ & $24.0(14.2,62.0)$ & 0.067 \\
\hline Stroke (\%) & $85(8.6)$ & $24(10.2)$ & $61(8.1)$ & 0.311 & $15(12.6)$ & $12(10.1)$ & 0.540 \\
\hline Paraplegia (\%) & $32(3.2)$ & $20(8.5)$ & $12(1.6)$ & $<0.001$ & $8(6.7)$ & $3(2.5)$ & 0.123 \\
\hline Tracheostomy (\%) & $45(4.5)$ & $23(9.7)$ & $22(2.9)$ & $<0.001$ & $9(7.6)$ & $7(5.9)$ & 0.605 \\
\hline Deep sternal wound infection (\%) & $14(1.4)$ & $7(3.0)$ & $7(0.9)$ & 0.029 & $5(4.2)$ & $1(0.8)$ & 0.213 \\
\hline 30-day mortality (\%) & $115(11.6)$ & $72(30.5)$ & $43(5.7)$ & $<0.001$ & $39(32.8)$ & $22(18.5)$ & 0.012 \\
\hline ICU Stay time (day) & $5.0(3.0,8.0)$ & $6.0(3.5,11.5)$ & $4.0(3.0,5.0)$ & $<0.001$ & $9.4 \pm 8.3$ & $5.8 \pm 5.1$ & $<0.001$ \\
\hline Hospital stay time (day) & $21.4 \pm 12.3$ & $24.3 \pm 16.3$ & $20.5 \pm 10.7$ & 0.001 & $24.0 \pm 16.7$ & $22.1 \pm 14.8$ & 0.351 \\
\hline
\end{tabular}

Data presented as $\mathrm{n}(\%)$, median (IQR), or mean \pm standard deviation

ICU intensive care unit; PSM propensity score matching

${ }^{*} P$ values indicate differences between stage $3 \mathrm{AKl}$ and control group patients. $P<0.05$ was considered statistically significant 
Table 5 Multivariable analysis of risk factors for stage 3 acute kidney injury with KDIGO

\begin{tabular}{|c|c|c|c|}
\hline Variable & OR & $95 \% \mathrm{Cl}$ & $P$ value \\
\hline Age (year) & 1.031 & $1.005-1.057$ & 0.018 \\
\hline BMI $\left(\mathrm{kg} / \mathrm{m}^{2}\right)$ & 1.063 & $0.993-1.138$ & 0.079 \\
\hline Hypertension & 1.033 & $0.539-1.982$ & 0.921 \\
\hline Previous cardiac surgery & 1.110 & $0.309-3.986$ & 0.837 \\
\hline Pericardial tamponade & 1.268 & $0.451-3.567$ & 0.653 \\
\hline MELD score $\geq 12$ & 1.883 & $0.758-4.679$ & 0.173 \\
\hline $\operatorname{PLT}\left(10^{9} / \mathrm{L}\right)$ & 1.002 & $0.998-1.007$ & 0.338 \\
\hline $\mathrm{s} C r(\mu \mathrm{mol} / \mathrm{L})$ & 1.005 & $1.000-1.010$ & 0.053 \\
\hline Bun (mmol/L) & 0.958 & $0.863-1.063$ & 0.417 \\
\hline $\mathrm{ALB}(\mathrm{g} / \mathrm{L})$ & 0.946 & $0.885-1.012$ & 0.104 \\
\hline Triglyceride (mmol/L) & 1.238 & $0.985-1.557$ & 0.067 \\
\hline INR & 1.689 & $0.698-4.084$ & 0.245 \\
\hline Total bilirubin ( $\mu \mathrm{mol} / \mathrm{L})$ & 0.993 & $0.972-1.015$ & 0.518 \\
\hline D-dimer (ng/mL) & 1.009 & $0.993-1.024$ & 0.266 \\
\hline TAR & 1.695 & $0.868-3.308$ & 0.122 \\
\hline CABG & 1.850 & $0.540-6.336$ & 0.327 \\
\hline CPB time $(\min )$ & 1.010 & $1.002-1.018$ & 0.013 \\
\hline Aortic cross-clamp time (min) & 0.996 & $0.988-1.005$ & 0.419 \\
\hline DHCA time (min) & 1.019 & $0.992-1.046$ & 0.163 \\
\hline $\begin{array}{l}\text { Drainage volume } 24 \mathrm{~h} \text { after surgery } \\
(\mathrm{mL})\end{array}$ & 1.000 & $1.000-1.001$ & 0.033 \\
\hline Paraplegia & 2.578 & $0.583-11.390$ & 0.212 \\
\hline
\end{tabular}

$P<0.05$ was considered statistically significant

$B M I$, body mass index; MELD model of end-stage liver disease; $P L T$ platelet; $S C r$ serum creatinine; $A L B$ albumin; INR international normalized ratio; TAR total arch replacement; $C A B G$ coronary artery bypass graft; $C P B$ cardiopulmonary bypass; $D H C A$ deep hypothermic circulatory arrest; $O R$ odds ratio; $\mathrm{Cl}$ confidence interval

were independent risk factors for developing postoperative stage 3 AKI (Table 5).

The follow-up of long-term mortality started on the day of surgery. 76 patients in the stage 3 AKI group and 45 patients in the control group died during the hospitalization period. As a result, a total of 872 patients survived the early postoperative period. The median follow-up time of this cohort was 20 months during which time a total of 11 patients (1.3\%) who did not develop postoperative AKI, 8 (0.9\%) with stage 1 AKI, 5 (0.6\%) with stage 2 AKI, and $29(3.3 \%)$ with stage 3 AKI passed away. 53 patients $(6.1 \%)$ who were lost to follow-up and 1 patient who committed suicide after hospital discharge were identified as censored data in the following outcome analysis. Our data indicated that the mortality correlated significantly with the severity of AKI defined by KDIGO criteria before and after matching $(P<0.001, P=0.003$; by log-rank test respectively), which were shown in Figs. 1 and 2. Multivariate Cox analysis for mortality (Table 6) revealed that the only stage 3 AKI (Hazard ratio 10.365; 95\% CI 4.208-25.528; $P<0.001$ ), but not stage 1 and 2 , was a significant and independent risk factor after adjusting for other major clinical factors that might increase postoperative AKI rate.

\section{Discussion}

In this study, we explored the consequences and risk factors for developing stage 3 AKI after ATAAD surgery. Compared with previous studies, our cohort was much larger and we applied the most updated and well accepted KDIGO criteria to define AKI. We found that advanced age, prolonged CPB duration, and higher drainage volume $24 \mathrm{~h}$ after surgery were independent predictors for developing postoperative stage $3 \mathrm{AKI}$. In addition, consistent with previous studies [6,7], our study confirmed that only stage $3 \mathrm{AKI}$, but not stage 1 or 2 , was associated with a higher postoperative mortality.

This correlation between AKI severity and long-term survival was also observed in other cardiothoracic operations [5]. A previous meta-analysis discovered that patients who suffered postoperative AKI were more likely to develop chronic kidney disease and end-stage renal disease, and the risk increased with the severity of AKI [10]. Therefore, above results underline the importance of identifying AKI in its early stages and offering appropriate treatment promptly before disease progression.

The incidence of postoperative AKI varied widely among different studies, partially due to the use of different AKI diagnostic criteria. A recent study reported that $24.0 \%$ of all patients developed stage 3 AKI after total arch replacement surgery with deep hypothermic circulatory arrest, including $15.4 \%$ patients who were treated with RRT [11], which were consistent with our results. However, Ko et al. reported that the incidence of developing stage 3 AKI after aortic arch surgery was 14\% and only $9 \%$ required RRT [7]. The lower rates might partially due to that patients who received emergency surgery were excluded from that study [12].

Consistent with previous studies, we identified that increased age was an independent risk factor for developing postoperative stage 3 AKI $[2,3,13]$. It has been well accepted in the field that advanced age is associated with structural and functional changes in the kidney including parenchymal mass loss, progressive glomerulosclerosis, tubulopathy, interstitial fibrosis, and afferent-efferent arteriolar shunts, which could all result in reduced renal function [14]. The reduced renal function rendered these patients more vulnerable to the hemodynamic changes during the surgery and it was not surprising that patients with advanced age were more likely to develop postoperative AKI after ATAAD surgery.

$\mathrm{CPB}$ duration was another well accepted independent risk factor for postoperative AKI in emergent thoracic aortic surgery. Englberger et al. discovered that longer 


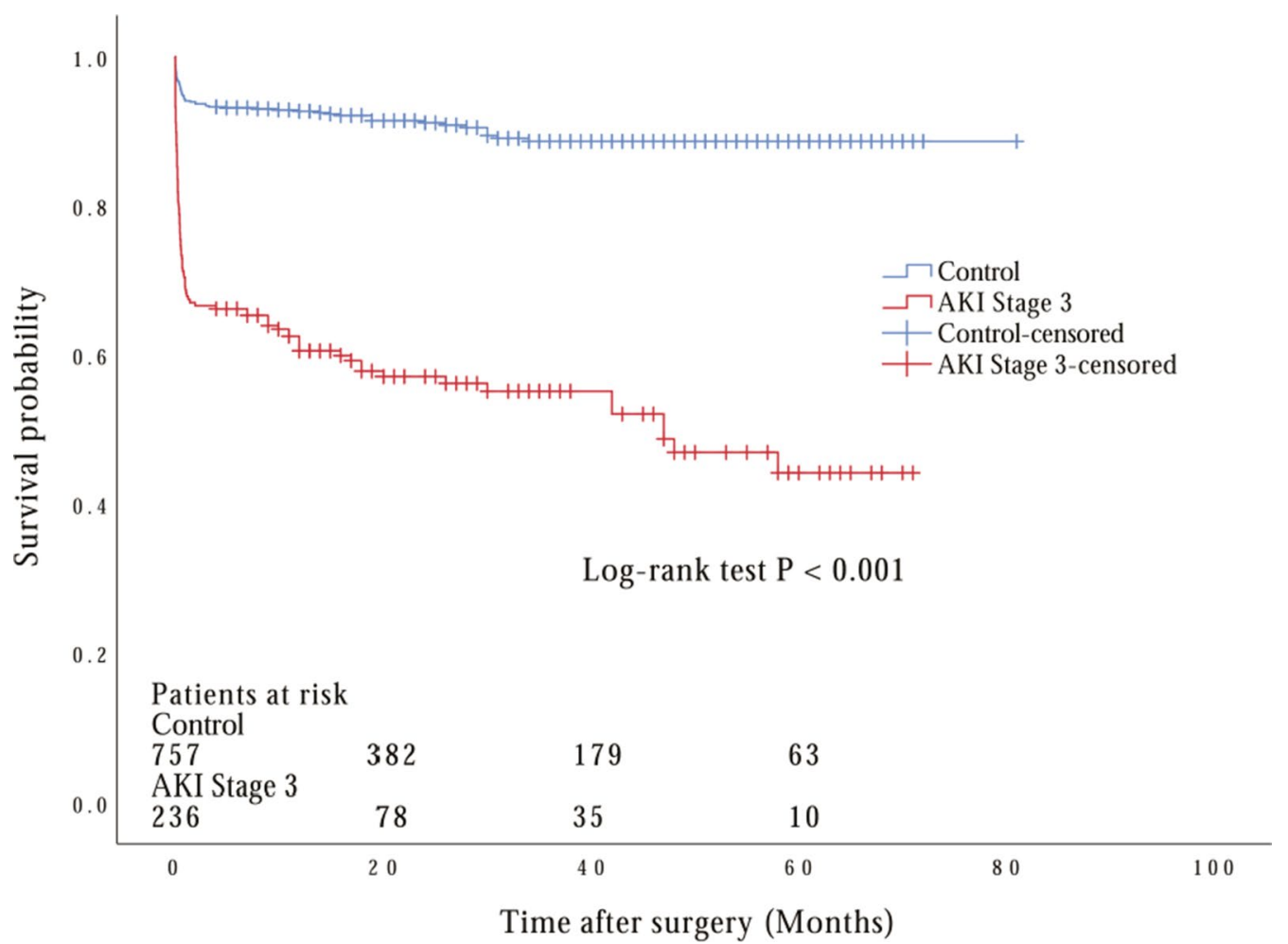

Fig. 1 Long-term survival estimates with the use of Kaplan-Meier method after operation for acute type A aortic dissection by severity of acute kidney injury (AKI). Kaplan-Meier estimation before propensity score matching. Significant overall difference is observed ( $P<0.001$ by log-rank test)

$\mathrm{CPB}$ time (per $10 \mathrm{~min}$ ) was associated with increasing postoperative AKI occurrence after studying 851 patients who received elective thoracic aortic operation [15]. Similarly, Roh et al. found that longer CPB duration was an independent risk factor for postoperative AKI among patients who received graft replacement of the thoracic aorta [3]. Furthermore, this correlation has been confirmed in some other studies $[16,17]$ and might be explained at least partially by the non-pulsatile blood flow and activation of inflammatory factors during the bypass [18]. However, more mechanism studies are needed to better understand this association before modification of the surgery process can be made.

Drainage volume $24 \mathrm{~h}$ after surgery was identified as another independent risk factor for postoperative stage 3 AKI by the logistic regression model in this study, which had been already recognized as a risk factor for AKI in previous studies [19]. Increases drainage volume can disrupt the homeostasis and induce pro-inflammatory states as well as increase oxidative stress which both can contribute to the pathogenesis of AKI [20]. Increasing evidences suggested that major perioperative transfusions of large amounts of packed red blood cells units and platelet units were associated with an increased incidence of AKI $[7,21,22]$. In line with this study, a recently published study showed that preoperative dual antiplatelet therapy increased the risk of major bleeding and transfusions, which ultimately increased the risk of AKI [23]. Therefore, decreasing $24 \mathrm{~h}$ drainage volume is important and may reduce the incidence of postoperative AKI.

\section{Limitations}

This study has some limitations. Firstly, although the sample size was large, the cohort was not homogeneous and might include some confounding factors in the baseline that were not recognized in the study. Secondly, our surgical technique evolved over the long study period, and surgeons with different surgical skills and experiences might also influence our results. Thirdly, the urine output was not examined in this study therefore the number of postoperative AKI patients might be underestimated. Therefore, further prospective multicenter studies are needed to better understand the association between postoperative AKI and disease prognosis before more effective strategies can be recommended.

\section{Conclusions}

This large cohort study underscores the high incidence of postoperative stage 3 AKI following ATAAD repair surgery and its association with worse outcome. Advanced 


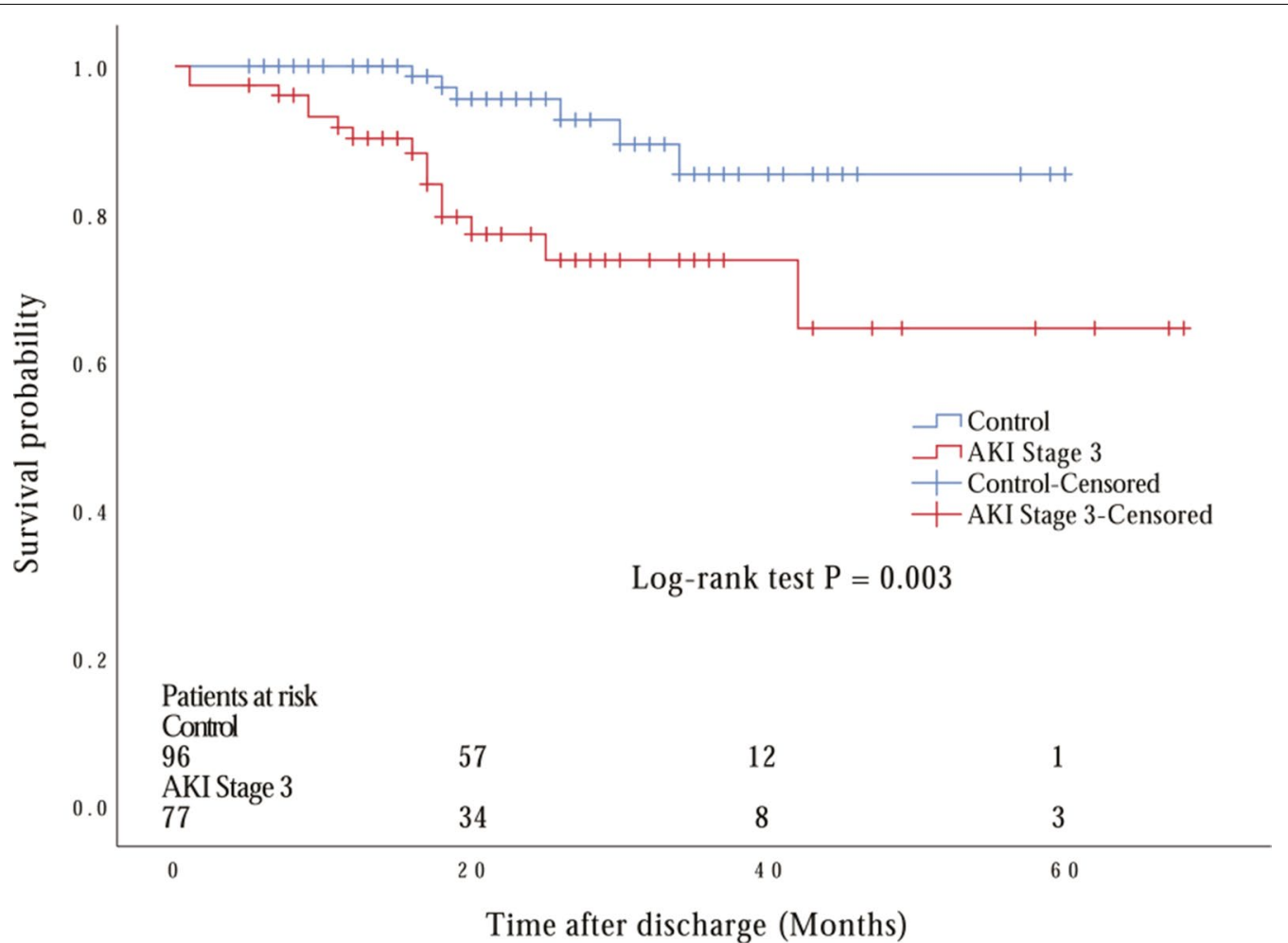

Fig. 2 Long-term survival estimates with the use of Kaplan-Meier method after discharge from hospital for acute type A aortic dissection by severity of acute kidney injury (AKI). Kaplan-Meier estimation after propensity score matching. Significant overall difference is observed $(P=0.003$ by log-rank test)

Table 6 Multivariate Cox analysis for mortality

\begin{tabular}{lccc}
\hline & Hazard ratio & 95\% Cl & P value \\
\hline Age (year) & 1.021 & $0.997-1.046$ & 0.085 \\
Hypertension & 1.592 & $0.728-3.484$ & 0.244 \\
Preoperative hemoglobin $(\mathrm{g} / \mathrm{L})$ & 0.993 & $0.982-1.005$ & 0.240 \\
Preoperative CRP $(\mathrm{mg} / \mathrm{dL})$ & 0.998 & $0.992-1.004$ & 0.454 \\
Preoperative $\mathrm{C} C \mathrm{(}(\mu \mathrm{mol} / \mathrm{L})$ & 0.998 & $0.995-1.001$ & 0.254 \\
Preoperative D-dimer $(\mathrm{ng} / \mathrm{mL})$ & 0.990 & $0.967-1.014$ & 0.419 \\
Pericardial tamponade & 2.280 & $0.749-6.944$ & 0.147 \\
CPB time (min) & 1.003 & $0.998-1.008$ & 0.241 \\
KDIGO stage 1 & 2.260 & $0.710-7.196$ & 0.167 \\
KDIGO stage 2 & 2.409 & $0.747-7.765$ & 0.141 \\
KDIGO stage 3 & 10.365 & $4.208-25.528$ & $<0.001$ \\
Ventilation time (hour) & 1.002 & $0.998-1.007$ & 0.307 \\
\hline P<0.05 was consded & & &
\end{tabular}

$P<0.05$ was considered statistically significant

$C R P$ c-reactive protein; $s C r$ serum creatinine; $C P B$ cardiopulmonary bypass; KDIGO Kidney Disease Improving Global Outcomes; Cl confidence interval

age, prolonged $\mathrm{CPB}$ time and increasing drainage volume $24 \mathrm{~h}$ after surgery were independent risk factors for developing postoperative stage 3 AKI.

\section{Abbreviations}

AKI: Acute kidney injury; ATAAD: Acute type A aortic dissection; KDIGO: Kidney Disease Improving Global Outcomes; OR: Odds ratio; Cl: Confidence interval; CPB: Cardiopulmonary bypass; SCr: Serum creatinine.

\section{Acknowledgements}

Not applicable.

\section{Authors' contributions}

DJW and ZGW conceived or designed the study. DJW, ZGW, MG, ZYW, and CC acquired, analyzed, or interpreted the data. ZGW, MG, ZYW, and CC drafted the manuscript. DJW, ZGW, and MG critically revised the manuscript for important intellectual content. LCL and LFZ performed the statistical analysis. All authors read and approved the final manuscript.

\section{Funding}

Not applicable.

\section{Availability of data and materials}

Data sharing in the current study are available from the corresponding author on reasonable request.

\section{Declarations}

\section{Ethics approval and consent to participate}

Ethical approval was obtained from Nanjing Drum Tower Hospital ethics committee. This retrospective study was conducted without informed consent for some objective reasons and was approved by the ethics committee. All procedures performed in studies were in accordance with the Declaration of Helsinki. 


\section{Consent for publication \\ Not applicable.}

\section{Competing interests}

The authors have declared that they have no competing interests.

\section{Author details}

${ }^{1}$ Department of Cardio-thoracic Surgery, Affiliated Drum Tower Hospital, Medical School of Nanjing University, Zhongshan Road 321, Nanjing 210008, China. ${ }^{2}$ Department of Psychiatry, The First Affiliated Hospital, Zhengzhou University, Zhengzhou, China.

Received: 2 September 2021 Accepted: 21 February 2022

Published online: 02 March 2022

\section{References}

1. Sinatra R, Melina G, Pulitani I, Fiorani B, Ruvolo G, Marino B. Emergency operation for acute type A aortic dissection: neurologic complications and early mortality. Ann Thorac Surg. 2001;71(1):33-8. https://doi.org/10. 1016/s0003-4975(00)01824-5.

2. Tsai HS, Tsai FC, Chen YC, et al. Impact of acute kidney injury on one-year survival after surgery for aortic dissection. Ann Thorac Surg. 2012;94(5):1407-12. https://doi.org/10.1016/j.athoracsur.2012.05.104.

3. Roh GU, Lee JW, Nam SB, Lee J, Choi JR, Shim YH. Incidence and risk factors of acute kidney injury after thoracic aortic surgery for acute dissection. Ann Thorac Surg. 2012;94(3):766-71. https://doi.org/10.1016/j.athor acsur.2012.04.057

4. Zhao H, Pan X, Gong Z, et al. Risk factors for acute kidney injury in overweight patients with acute type $A$ aortic dissection: a retrospective study. J Thorac Dis. 2015;7(8):1385-90. https://doi.org/10.3978/j.issn.2072-1439. 2015.07.19.

5. Hobson CE, Yavas S, Segal MS, et al. Acute kidney injury is associated with increased long-term mortality after cardiothoracic surgery. Circulation. 2009;119(18):2444-53. https://doi.org/10.1161/CIRCULATIONAHA.108. 800011.

6. Sasabuchi Y, Kimura N, Shiotsuka J, et al. Long-term survival in patients with acute kidney injury after acute type A aortic dissection repair. Ann Thorac Surg. 2016;102(6):2003-9. https://doi.org/10.1016/j.athoracsur. 2016.05.006.

7. Ko T, Higashitani M, Sato A, et al. Impact of acute kidney injury on early to long-term outcomes in patients who underwent surgery for type A acute aortic dissection. Am J Cardiol. 2015;116(3):463-8. https://doi.org/10. 1016/j.amjcard.2015.04.043.

8. Schoenrath F, Laber R, Maralushaj M, et al. Survival, neurologic injury, and kidney function after surgery for acute type A aortic dissection. Thorac Cardiovasc Surg. 2016;64(2):100-7. https://doi.org/10.1055/s-0035-15635 36.

9. Wang Z, Ge M, Chen T, et al. Acute kidney injury in patients operated on for type A acute aortic dissection: incidence, risk factors and short-term outcomes. Interact Cardiovasc Thorac Surg. 2020;31(5):697-703. https:// doi.org/10.1093/icvts/ivaa164

10. Coca SG, Singanamala S, Parikh CR. Chronic kidney disease after acute kidney injury: a systematic review and meta-analysis. Kidney Int. 2012;81(5):442-8. https://doi.org/10.1038/ki.2011.379.

11. Li CN, Ge YP, Liu H, et al. Blood transfusion and acute kidney injury after total aortic arch replacement for acute Stanford type A aortic dissection. Heart Lung Circ. 2021. https://doi.org/10.1016/j.hlc.2021.05.087.

12. Geirsson A, Szeto WY, Pochettino A, et al. Significance of malperfusion syndromes prior to contemporary surgical repair for acute type A dissection: outcomes and need for additional revascularizations. Eur 」 Cardiothorac Surg. 2007;32(2):255-62. https://doi.org/10.1016/j.ejcts. 2007.04.012.

13. Helgason D, Helgadottir S, Ahlsson A, et al. Acute kidney injury after acute repair of type A aortic dissection. Ann Thorac Surg. 2021;111(4):1292-8. https://doi.org/10.1016/j.athoracsur.2020.07.019.

14. Cowen LE, Hodak SP, Verbalis JG. Age-associated abnormalities of water homeostasis. Endocrinol Metab Clin North Am. 2013;42(2):349-70. https://doi.org/10.1016/j.ecl.2013.02.005
15. Englberger L, Suri RM, Greason KL, et al. Deep hypothermic circulatory arrest is not a risk factor for acute kidney injury in thoracic aortic surgery. J Thorac Cardiovasc Surg. 2011;141(2):552-8. https://doi.org/10.1016/j. jtcvs.2010.02.045

16. Heringlake $M$, Charitos El, Erber $K$, Berggreen AE, Heinze H, Paarmann $H$. Preoperative plasma growth-differentiation factor-15 for prediction of acute kidney injury in patients undergoing cardiac surgery. Crit Care. 2016;20(1):317. https://doi.org/10.1186/s13054-016-1482-3.

17. $\mathrm{Ng} \mathrm{RR,} \mathrm{Chew} \mathrm{ST,} \mathrm{Liu} \mathrm{W,} \mathrm{Shen} \mathrm{L,} \mathrm{Ti} \mathrm{LK.} \mathrm{Identification} \mathrm{of} \mathrm{modifiable} \mathrm{risk}$ factors for acute kidney injury after coronary artery bypass graft surgery in an Asian population. J Thorac Cardiovasc Surg. 2014;147(4):1356-61. https://doi.org/10.1016/j.jtcvs.2013.09.040.

18. Cremer J, Martin M, Redl H, et al. Systemic inflammatory response syndrome after cardiac operations. Ann Thorac Surg. 1996;61 (6):1714-20. https://doi.org/10.1016/0003-4975(96)00055-0.

19. Stone GW, Clayton TC, Mehran R, et al. Impact of major bleeding and blood transfusions after cardiac surgery: analysis from the Acute Catheterization and Urgent Intervention Triage strategY (ACUITY) trial. Am Heart J. 2012;163(3):522-9. https://doi.org/10.1016/j.ahj.2011.11.016.

20. Karkouti K, Wijeysundera DN, Yau TM, et al. Acute kidney injury after cardiac surgery: focus on modifiable risk factors. Circulation. 2009;119(4):495-502. https://doi.org/10.1161/CIRCULATIONAHA.108. 786913.

21. Karkouti K, Wijeysundera DN, Yau TM, et al. Influence of erythrocyte transfusion on the risk of acute kidney injury after cardiac surgery differs in anemic and nonanemic patients. Anesthesiology. 2011;115(3):523-30. https://doi.org/10.1097/ALN.0b013e318229a7e8

22. Kindzelski BA, Corcoran P, Siegenthaler MP, Horvath KA. Postoperative acute kidney injury following intraoperative blood product transfusions during cardiac surgery. Perfusion. 2018;33(1):62-70. https://doi.org/10. 1177/0267659117712405.

23. Hansson EC, Geirsson A, Hjortdal V, et al. Preoperative dual antiplatelet therapy increases bleeding and transfusions but not mortality in acute aortic dissection type A repair. Eur J Cardiothorac Surg. 2019;56(1):182-8. https://doi.org/10.1093/ejcts/ezy469.

\section{Publisher's Note}

Springer Nature remains neutral with regard to jurisdictional claims in published maps and institutional affiliations.

Ready to submit your research? Choose BMC and benefit from

- fast, convenient online submission

- thorough peer review by experienced researchers in your field

- rapid publication on acceptance

- support for research data, including large and complex data types

- gold Open Access which fosters wider collaboration and increased citations

- maximum visibility for your research: over $100 \mathrm{M}$ website views per year

At BMC, research is always in progress.

Learn more biomedcentral.com/submissions 